\title{
A Method to Accurately Determine the Methane Enrichment Zone of a Longwall Coal Mine
}

\author{
Guorui Feng $\mathbb{D},{ }^{1}$ Ao Zhang, ${ }^{2}$ Shengyong Hu $\mathbb{D},{ }^{2}$ Xiangqian Guo, ${ }^{3,4}$ Chao Li, ${ }^{3,4}$ Guocai Hao, ${ }^{2}$ \\ and Zhen $\mathbf{L i}^{2}$ \\ ${ }^{1}$ College of Mining Engineering, Taiyuan University of Technology, Taiyuan 030024, China \\ ${ }^{2}$ College of Safety and Emergency Management Engineering, Taiyuan University of Technology, Taiyuan 030024, China \\ ${ }^{3}$ Shanxi Jincheng Anthracite Mining Group Co. Ltd., Jincheng 048000, China \\ ${ }^{4}$ State Key Laboratory of Coal and CBM Co-Mining, Jincheng 048006, China \\ Correspondence should be addressed to Shengyong Hu; hsyztx@163.com
}

Received 10 September 2018; Revised 16 November 2018; Accepted 29 November 2018; Published 27 February 2019

Guest Editor: Bisheng Wu

Copyright (c) 2019 Guorui Feng et al. This is an open access article distributed under the Creative Commons Attribution License, which permits unrestricted use, distribution, and reproduction in any medium, provided the original work is properly cited.

Large numbers of gobs are produced as a result of underground longwall mining, and a large amount of these gobs is known to contain methane gas reserves. The efficient drainage of these methane resources is directly dependent on accurately determining the methane enrichment zone (MEZ) in longwall mining gobs. In this study, a method for accurately determining the MEZ within the zone of interconnected fractures, which utilized a surface directional borehole (SDB) technique, was proposed. The SDB was designed and implemented in a longwall gob located in the Sihe Coal Mine in China's Shanxi Province. The trajectory of the SDB constantly varied in the different overlying stratum layers and locations above the gob. The methane flow rate and concentration from the SDB, along with the methane concentration in the upper corner of the longwall face, were monitored and obtained as the longwall face advanced. Then, by analyzing the acquired data of the different horizontal and vertical positions of the SDB, the accurate locations of the MEZ within the zone of interconnected fractures were determined. There were the methane decrease zone (MDZ) and methane shortage zone (MSZ) below and above the MEZ, respectively. The results showed that in the MEZ, both the methane flow rate and concentration displayed slight decreasing trends and maintained high levels as the distance from the roof of the coal seam increased. In the MDZ, a sharp decline was observed in the methane flow rate. However, a relatively high methane concentration had still been maintained. In the MSZ, both the methane flow rate and concentration displayed dramatic fluctuation and relatively low levels. The average methane flow rates in the MEZ were determined to be 1.3 and 1.6 times higher than those in the MDZ and MSZ, respectively.

\section{Introduction}

Coal is one of the most important global energy sources and contributes to up to $70 \%$ of China's primary energy production and consumption [1]. Underground mines account for $90 \%$ of the total amount of coal mines in China, and highly gassy mines share $51 \%$ of the total [2-4]. As a result, a large amount of methane is released in the longwall gobs of these coal mines and then flows into the longwall faces as the mining processes advance [5]. Methane is a dangerously explosive gas, as well as a clean energy resource [6-8]. The extraction of methane gas from mining gobs not only alleviates the energy shortage issue in China but also serves to prevent the methane purity in the atmosphere of longwall mines from exceeding the recommended safety levels [9-12]. However, methane extraction effects directly rely on the accurate determinations of the MEZ above the longwall gobs in longwall coal mines $[2,13,14]$.

As the underground working faces advance, the overlying strata form "three zones" in the vertical direction, which are referred to as the caved zone, fractured zone, and continuous zone [15-20]. Among these three zones, the methane within the gobs is able to flow into the caved zone as well as the lower and middle parts of the fractured zone due to the 


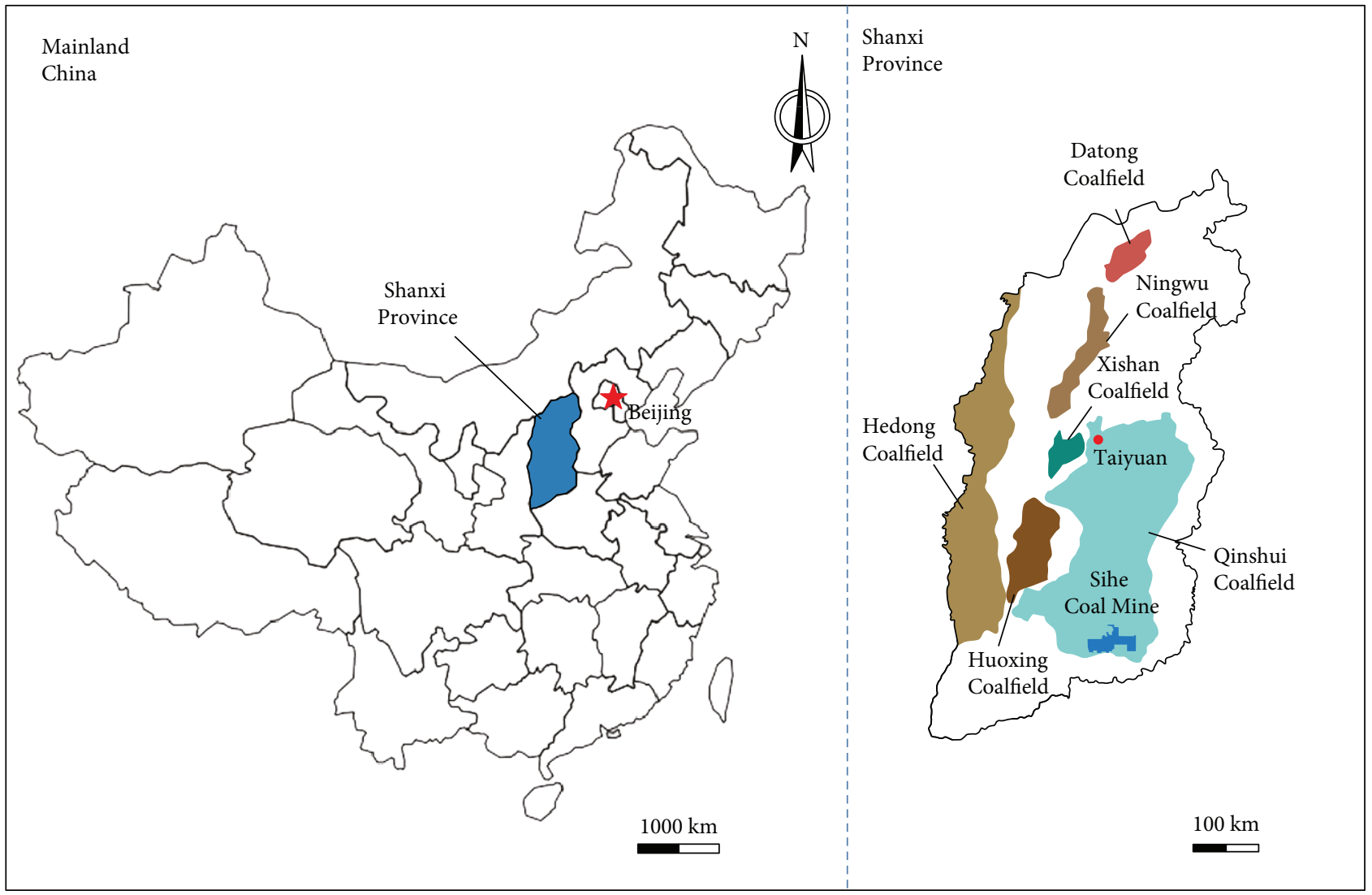

Figure 1: Location of the Sihe Coal Mine.

vertical interconnected fractures within the two zones [19, 21]. Singh and Yadav [22] presented a fractured zone profile induced by coal mining using a viscoelastic model. Das [23] studied the fracture zone divisions of overlying strata by observing and proposing the concept of weighting and caving zone. Qian and Shi [24] proposed the caved zone, the fractured water-inflow zone, and the continuous zone along the vertical direction (from the bottom to the top) in mining gobs. Christopher [25] studied fracture space divisions by dividing the overlying strata into the caving zone, the fracture zone, the dilated zone, and the confined zone. Yuan et al. [26] presented the concept that circular overlying zone existed in a longwall mining panel which could be used for efficient methane extraction. Guo et al. [27] proposed an annular fractured zone for methane drainage by establishing a CFD model based on methane gas drainage conditions. Li et al. [28] studied the distributions of elliptic paraboloid zone using physical simulation experiments and numerical approaches. Gao et al. [29] studied a pear-shaped region around the mining seam using a numerical approach. Qin et al. [30] conducted a research regarding the heights of caved and fractured zones in a longwall panel by employing a CFD numerical method. Qu et al. [31] presented the concepts of the fractured gas-interflow zone, de-stressed gas-desorption zone, and confined gas-adsorption zone based on a conceptual model of overburden rock of a longwall panel. Wang et al. [32, 33] studied the methane flow characteristics of a longwall panel by using building numerical models. Feng et al. [34] studied the methane flow space in abandoned gobs based on physical simulation experiments. However, almost all of these researches related to the MEZ had mainly adopted methods using empire formula, mathematical models, and simulation experiments. The results acquired by these studies contained a variety of assumptions which tended to usually result in some differences from the real field situations. Therefore, in order to achieve more accurate determination results, this study proposed a method which was based on actual MEZ field tests.

In this study, a method which utilized SDB to accurately determine the MEZ within the zone of interconnected fractures was proposed and implemented in the Sihe Coal Mine of China's Shanxi Province. The SDB was designed in a longwall face, and the trajectory of the SDB constantly varied in the different overlying stratum layers and locations above the longwall face. The methane flow rate and concentration from the SDB, as well as the methane concentration in the upper corner of the longwall face, were monitored and obtained as the longwall face advanced. The positions of the MEZ in the zone of interconnected fractures were then accurately determined by analyzing the obtained data.

\section{Description of the Studied Coal Mine}

The Sihe Coal Mine is located in the southern marginal part of the Qinshui Coalfield in China's Shanxi Province, as shown in Figure 1. It has a length of approximately $23 \mathrm{~km}$ 


\begin{tabular}{|c|c|c|c|}
\hline Depth (m) & Thickness (m) & Lithology & Rock columnar \\
\hline 274.0 & 26.0 & Sandy mudstone & \\
\hline 291.0 & 17.0 & Medium sandstone & \\
\hline 311.1 & 20.1 & Sandy mudstone & \\
\hline 322.7 & 11.6 & Fine sandstone & \\
\hline 323.2 & 0.5 & Siltstone & \\
\hline 341.9 & 18.7 & Sandy mudstone & \\
\hline 354.3 & 12.4 & Fine sandstone & \\
\hline 359.9 & 5.6 & Sandy mudstone & \\
\hline 363.7 & 3.8 & Siltstone & \\
\hline 365.8 & 2.1 & Sandy mudstone & \\
\hline 370.0 & 4.2 & Medium sandstone & \\
\hline 371.1 & 1.1 & Fine sandstone & \\
\hline 373.6 & 2.5 & Sandy mudstone & \\
\hline 375.2 & 1.6 & Medium sandstone & \\
\hline 376.0 & 0.8 & Sandy mudstone & \\
\hline 385.2 & 9.2 & Medium sandstone & \\
\hline 398.2 & 13.0 & Fine sandstone & \\
\hline 406.7 & 8.5 & Siltstone & \\
\hline 410.1 & 3.4 & Sandy mudstone & \\
\hline 416.2 & 6.1 & 3\# coal seam & \\
\hline 427.5 & 11.3 & Sandy mudstone & \\
\hline
\end{tabular}

Figure 2: Stratigraphic column of the studied mine.

in a west-to-east direction and width of almost $12 \mathrm{~km}$ in a north-to-south direction and covers a total area of approximately $230 \mathrm{~km}^{2}$. The Sihe Coal Mine is considered to be a gassy coal mine, with a methane content of approximately $13 \mathrm{~m}^{3} / \mathrm{t}$ and a pressure rate of approximately $0.29 \mathrm{MPa}$. The estimated methane resources measure $1.03 \times 10^{10} \mathrm{~m}^{3}$.

The main minable coal seam in the Sihe Coal Mine is the \#3 Coal Seam, which is located in the lower group of the Shanxi Formation. There is approximately $1.5 \times 10^{9}$ t of coal resources stored in the Sihe Coal Mine, and $2.1 \times 10^{8} \mathrm{t}$ of that total is minable in the \#3 Coal Seam. The average number of dips in the \#3 Coal Seam is 5 , which are nearly horizontal and considered to be stable within the mining area. The average thickness of the \#3 Coal Seam is approximately $6.1 \mathrm{~m}$. The thicknesses of immediate roof and floor areas of the \#3 Coal Seam are approximately $3.4 \mathrm{~m}$ and $11.3 \mathrm{~m}$, respectively, and consist primarily of sandy mudstone. A typical stratigraphic column from this coal mine is shown in Figure 2.

A current working face is situated in the Sihe Coal Mine, and the layout of this working face is shown in Figure 3. The working face's mining seam was the \#3 Coal Seam, and its depth and thickness were about $416.2 \mathrm{~m}$ and $6.1 \mathrm{~m}$, respectively. The length of the working face in the direction of the current mining was $1281.5 \mathrm{~m}$, and the incline width was $301.5 \mathrm{~m}$. A longwall mining method had been adopted in the working face, and a "U"-type ventilation system was in place.

\section{Method}

In the study area, it was observed that as the working face advanced, the corresponding positions of the SDB continuously varied in both the horizontal and vertical directions. As a result, the gob methane within different positions of the overlying strata above the formed gob could be extracted by the SDB. It was found that both the methane flow rate and concentration displayed major variations during the entire SDB drainage period. Therefore, based on these data variations, the zones with different methane flow rates and concentrations could be successfully determined. Then, the locations of the MEZ within the zone of interconnected fractures could be accurately identified by combining the advancing distances and their corresponding trajectory locations within the overlying strata. Moreover, methane drainage effects were found to directly influence the methane concentration of the upper corner of the working face. Therefore, based on its variations during the entire drainage period, 


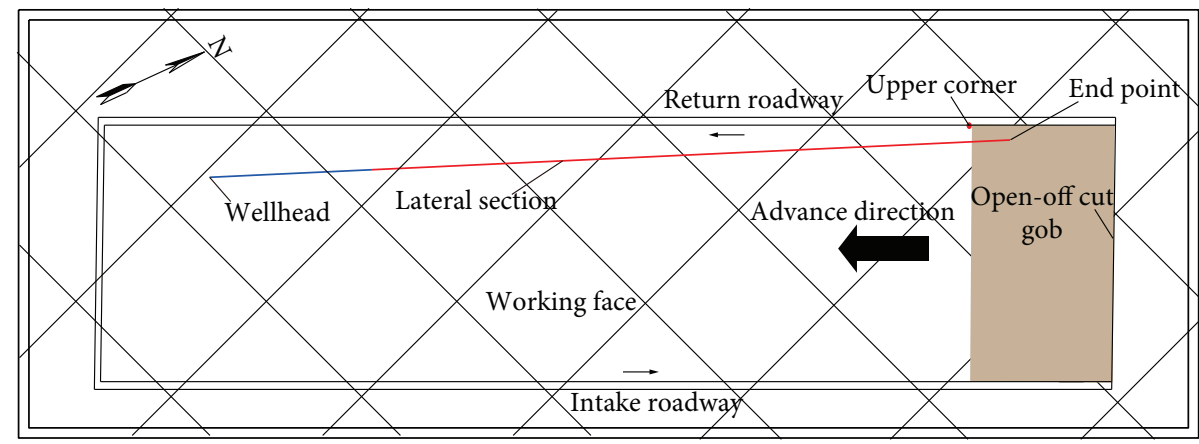

FIGURE 3: Layout of the working face.

the accuracy of this method could be further verified from another aspect.

In this study, based on the abovementioned principle, an SDB was designed and implemented in the studied working face of the Sihe Coal Mine. The trajectories of the SDB along the mining direction and within the overlying strata of the working face are shown in Figures 3 and 4, respectively. The SDB included a vertical section, build section, and lateral section, and the lateral section was selected as the study part. As shown in Figures 3 and 4, the study part (lateral section) of the SDB was not parallel to the return roadway. However, its horizontal positions were found to have become gradually closer to the return roadway of the working face as the SDB stretched from its starting position to its ending position. Similarly, the vertical positions of the study part were observed to have become gradually farther away from the coal seam as the SDB stretched from its starting position to its ending position. In detail, the distances between the horizontal positions and the return roadway and the distances between the vertical positions and the coal seam varied from 13.5 to $48.7 \mathrm{~m}$ and 10.62 to $55.56 \mathrm{~m}$, respectively. As can be seen in Figure 4, the study part was located above the coal seam and was $805 \mathrm{~m}$ in length. The distance from the SDB end point to the open-off cut of the working face was approximately $138 \mathrm{~m}$. It was observed that the gas began to flow through the SDB when the working face had advanced past its end point by approximately $390 \mathrm{~m}$.

\section{Results and Discussion}

4.1. Relationship between the Methane Flow Rate and Concentration and the Advancing Distances. Though the fractures within the caved zone and the lower and middle parts of the fractured zone are interconnected, the methane contents and concentrations of different locations within the zone of interconnected fractures are significant as the mining processes. Based on this, the detailed divisions of the zone of interconnected fractures were achieved by capturing the methane flow rates and concentrations through the SDB over the entire drainage period. Also, the methane concentration of the upper corner in the longwall face was monitored continuously at the same time. The detailed variations in the methane flow rate and concentration as the

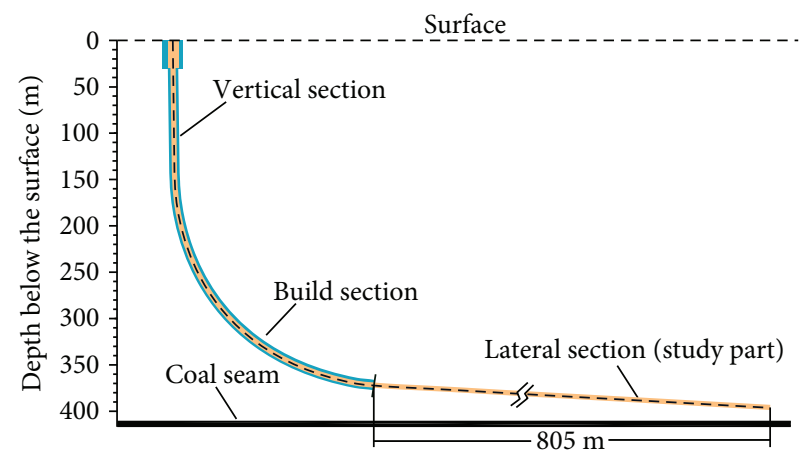

FIgUre 4: Trajectory of the SDB.

working face advancement distance increased are shown in Figure 5.

Based on the obvious differences of methane flow rate and concentration under different locations in the zone of interconnected fractures, the zone boundaries among the different zones were determined. It can be seen in Figure 5 that both the methane flow rate and concentration displayed the highest levels when the advance distance range was approximately 600 to $810 \mathrm{~m}$. The zone with the highest methane flow rate and concentration was considered as the MEZ. In the MEZ, both the methane flow rate and concentration displayed gradual decreasing trends despite some fluctuation. For example, the methane flow rate and concentration had declined from $1,285 \mathrm{~m}^{3} / \mathrm{h}$ to $973 \mathrm{~m}^{3} / \mathrm{h}$ and from $85 \%$ to $75 \%$, respectively. The average methane flow rate and concentration in the MEZ were determined to be $1135 \mathrm{~m}^{3} / \mathrm{h}$ and $75.5 \%$, respectively. In addition, there was a dramatic fall (from $1,174 \mathrm{~m}^{3} / \mathrm{h}$ to $476 \mathrm{~m}^{3} / \mathrm{h}$ ) in the methane flow rate and a slight decrease (from $90 \%$ to $72 \%$ ) in the methane concentration, when the working face advancement distance ranged between approximately 390 and $600 \mathrm{~m}$. In this study, this zone was referred as the methane decrease zone (MDZ) and was located below the MEZ. The average methane flow rate and concentration in the MDZ were determined to be $906 \mathrm{~m}^{3} / \mathrm{h}$ and $77 \%$, respectively. Furthermore, low methane flow rates and concentrations were observed when the working face advancement distance range was approximately 810 to $1,046 \mathrm{~m}$. This zone was referred to as the methane shortage zone (MSZ) in this study and was located above the MEZ. In 


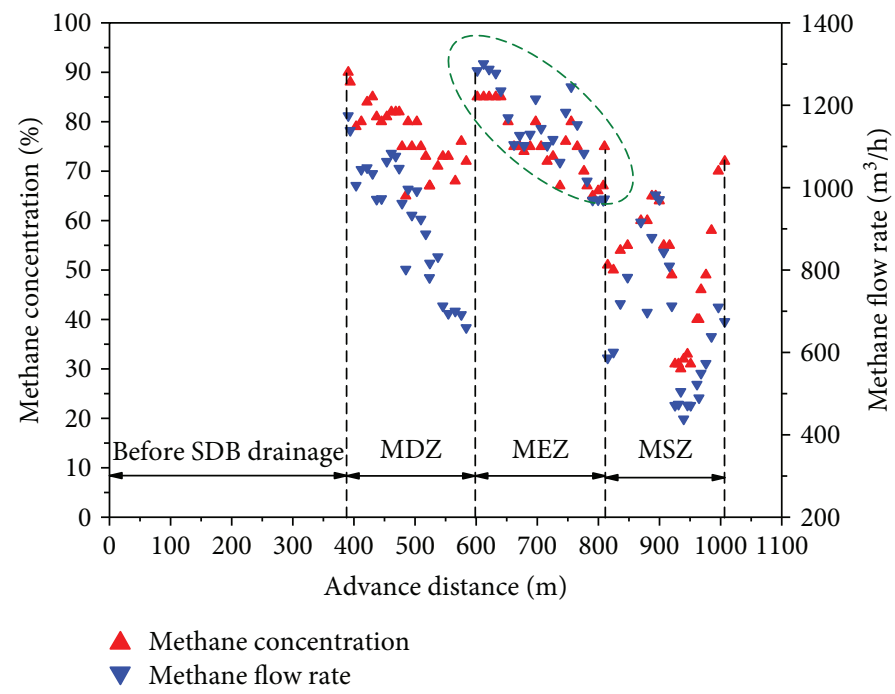

FIGURE 5: Methane flow rate and concentration variations with the increases in the working face advancement distances.

the MSZ, both the methane flow rate and concentration were found to display dramatic fluctuations and averaged only $710 \mathrm{~m}^{3} / \mathrm{h}$ and $54.5 \%$, respectively.

The bulking-factor-controlled caving model was widely used to estimate the height of the caved zone $[35,36]$. The height of the caved zone $\left(H_{c}\right)$ depends on the mining thickness $(M)$ and bulking factor $(k)$ and can be expressed as

$$
H_{c}=\frac{(1-\lambda) M}{k-1},
$$

where $0 \leq \lambda \leq 1$ is the sagging coefficient. In the Sihe Coal Mine, the sagging coefficient $(\lambda)$, bulking factor $(k)$, and mining thickness $(M)$ is $0,1.20-1.25$, and $6.1 \mathrm{~m}$, respectively. Based on equation (1), the height range of the caved zone was calculated to be 24.4 to $30.5 \mathrm{~m}$.

Besides, in accordance with the results of previous related studies [37,38], the heights of the overburden zones could be expressed and estimated by the following:

$$
\begin{aligned}
& H_{c}=\frac{100 M}{0.49 M+19.12} \pm 4.71, \\
& H_{f}=\frac{100 M}{1.19 M+28.57} \pm 4.76,
\end{aligned}
$$

where $H_{c}$ and $H_{f}$ represent the heights (m) of the caved zone and the fractured zone, respectively, and $M$ denotes the mining thickness (m). Therefore, based on equation (2) the height range of the caved zone was confirmed to be 22.9 to $32.3 \mathrm{~m}$, which coincides with the result calculated by equation (1). In addition, based on equation (3), the height range of the fractured zone was 60.6 to $83.6 \mathrm{~m}$.

Also, the results of previous related studies $[28,34,39]$ had revealed that the methane concentrations in the MEZ could be expressed as

$$
C=a e^{b},
$$

where $C$ represents the methane concentration in the MEZ; $a$ is constant; and $b$ represents the height from the floor.

Equation (4) indicated that the methane concentration in the MEZ had displayed an exponential growth trend with the increases in the vertical height. Furthermore, the MEZ had been located in the top of the fractured zone in previous studies. However, in this study, a gradual decreasing trend of the methane concentration was observed as the vertical height within the MEZ increased (Figure 6), and the MEZ was located below the MSZ and above the MDZ. The determination of the MEZ distribution, as well as the correlation between the methane concentrations and the vertical height, had been achieved using theoretical analysis, simulation experiments, and empirical formula in the previous studies $[28,34,39]$. Also, in the previous studies, the actual conditions had been simplified and the methane enrichment process was not dynamic. Therefore, there was enough time for the methane to rise in the MEZ owing to its low density when compared with the surrounding air under the aforementioned conditions. However, this study found that under the actual conditions in the examined mine, both the working face advancement and the methane drainage processes were continuous, and the fractured zone and MEZ were continuously evolving. It was observed that the methane gas within the gobs potentially did not quickly flow into the top of the fracture in great amounts due to the fact that vertical stress had been recovered and the stratum fractures behind the working face had gradually closed [5, $27,40]$. Instead, most of the methane had flowed into the zone where the stratum fractures were stretched having been induced by the mining activities. Therefore, it was concluded that the MEZ may have been characterized by smaller zone ranges in situ.

The detailed methane concentration variation of the upper corner in the studied working face as the advancement distance of the working face had increased is detailed in Figure 7. As can be seen in the figure, it was evident that 


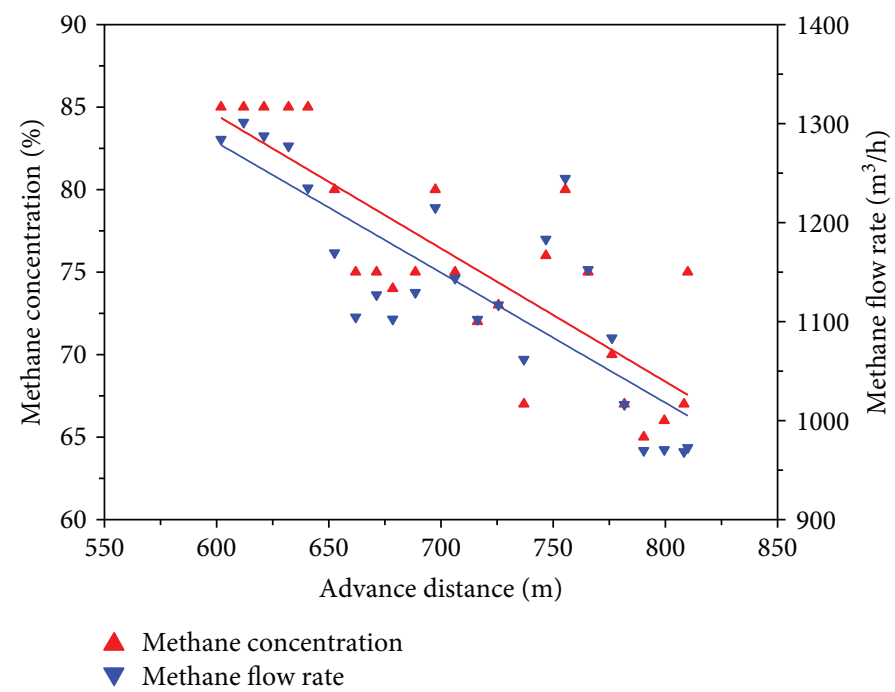

Figure 6: Methane flow rate and concentration variations within the MEZ.

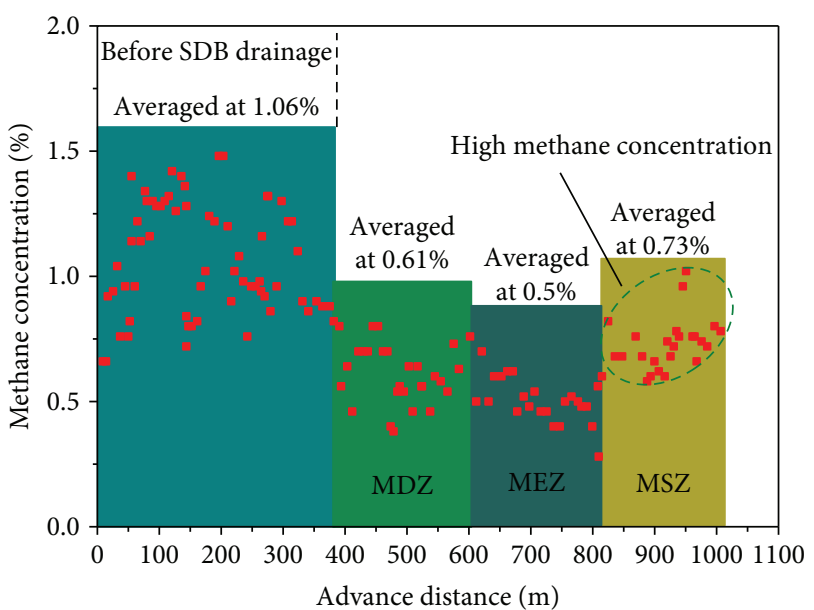

Methane concentration of the upper corner

FIGURE 7: Methane concentration variations of the upper corner as the working face advancement distance increased.

the methane concentration in the upper corner was relatively high before the SDB began the drainage process when compared to after the drainage process was in progress. Prior to the SDB beginning the methane gas drainage, the average methane concentration in the upper corner was determined to be $1.06 \%$. In contrast, it was observed to have decreased to $0.60 \%$ during the drainage process. The average methane concentrations of the upper corner in the three zones were $0.61 \%, 0.50 \%$, and $0.73 \%$, respectively, which indicated that methane had been efficiently extracted in the MEZ.

4.2. MEZ Distribution. The location of the MEZ was obtained by analyzing the relationships between the methane flow rate and concentration and the working face advancement distances (Figure 5). Then, based on the obtained results, the location of the MEZ could be accurately determined by combining the advancement distances and their corresponding trajectory locations within the overlying strata. Figure 8 illustrates the correlations between the zone divisions and the zone locations. The horizontal and vertical location ranges in which the three zones corresponded were obtained through combining the results shown in Figure 8 with the mining distances. The horizontal boundaries of the MEZ were determined to range between 42.09 and $54.05 \mathrm{~m}$ from the return roadway, and the vertical boundaries ranged from 35.29 to $47.31 \mathrm{~m}$ from the roof of the coal seam. Moreover, the horizontal boundaries of the MDZ and MSZ ranged between 31.05 and $42.09 \mathrm{~m}$ and 54.05 to $65.27 \mathrm{~m}$ from the return roadway, respectively. It was determined in this study that the vertical boundaries of the MDZ and MSZ ranged from 24.94 to $35.29 \mathrm{~m}$ and from 47.31 to $75.17 \mathrm{~m}$ from the roof of the coal seam, respectively.

The strata located in the central section of the panel tended to be compacted, and the fractures at the edges of the incline direction which were maintained after the development of the overburden rocks were relatively stable in the areas where the mining activities had been implemented. The circle-shape zone near the corners of the panel where the vertical fractures were well-developed and maintained was referred to as the "abscission circle" [30, 41], as detailed in Figure 9.

Figure 8 illustrates the locations of the three zones above the gob, and Figure 10 shows the schematics of the three zone divisions in the incline profile above the gob. As can be seen in Figures 8 and 10, the horizontal location of the MEZ was within the abscission circle. However, its vertical location was in the lower part of the fractured zone (rock blocks). In the MEZ, fractures were well-developed and produced considerable gas migration channels which ensured the highest methane extraction effects. The horizontal location of the MDZ was near the return roadway and was also located within the abscission circle. Its vertical location was situated on the borders of the caved and fractured zones. There was found to be an abrupt drop in 


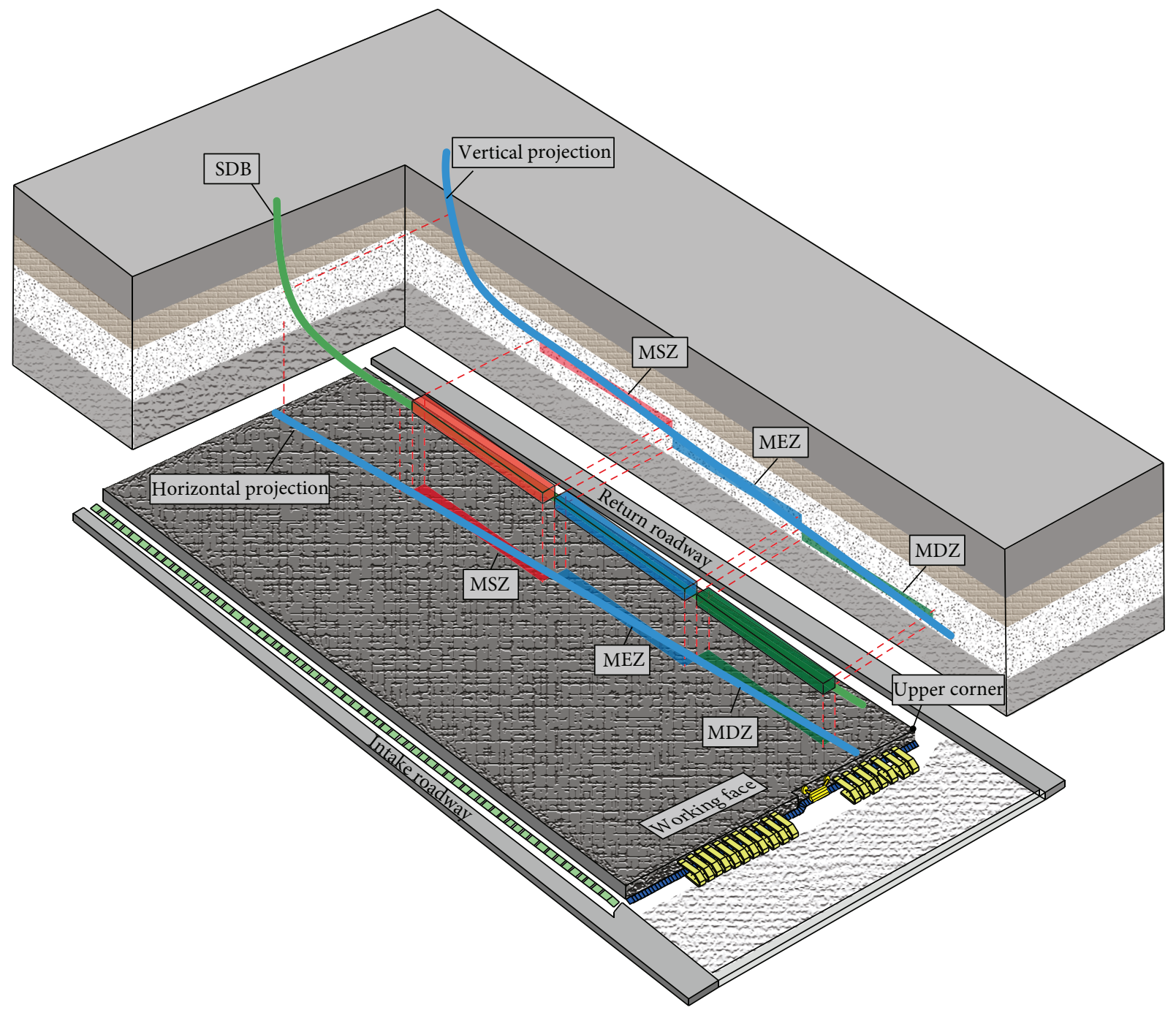

FIgURE 8: Space locations of the MDZ, MEZ, and MSZ.

permeability on the borders of the two zones [21], which caused the methane flow rate to dramatically decline in the MDZ. The MSZ was located in the compacted area in the horizontal direction, and the middle part of the fractured zone (through-going vertical fractures) in the vertical direction. The methane gas flow was therefore reduced in the MSZ due to the poorly developed vertical fractures in this zone. As a result, the methane flow rate and purity were found to be low in the MSZ. Among the three zones, the highest methane flow rate and purity were observed in the MEZ. It was concluded that improved methane drainage effects could be achieved when the lateral section of the SDB, or a high-level suction tunnel, was arranged in the MEZ.

\section{Conclusions}

A method for determining the methane enrichment zone (MEZ) within the zone of interconnected fractures of a longwall coal mine was proposed and implemented. In the proposed method, an SDB was designed and implemented in a longwall face located in the Sihe Coal Mine of China's Shanxi
Province. The trajectory of the SDB varied constantly in the different overlying stratum layers and locations above the mine gob. The data regarding the methane flow rate and concentration obtained from the SDB and the methane concentrations in the upper corner as the longwall face advanced were monitored and obtained simultaneously.

The MEZ had been accurately determined in the examined mine. In the MEZ, both the methane flow rate and concentration were found to be the highest despite falling slightly as the active mining face distance increased. It was observed that two zones existed below and above the MEZ, which were referred to as the methane decrease zone (MDZ) and the methane shortage zone (MSZ), respectively. Within the MDZ, both the methane flow rate and concentration displayed gradual decreasing trends as the distance of the mining face advancement increased. Within the MSZ, the methane flow rate and concentration were determined to be lowest among the three zones and also had displayed dramatic fluctuation.

Among the three zones, the highest methane flow rate and purity were identified to be found in the MEZ. The methane concentration in the upper corner was found to 


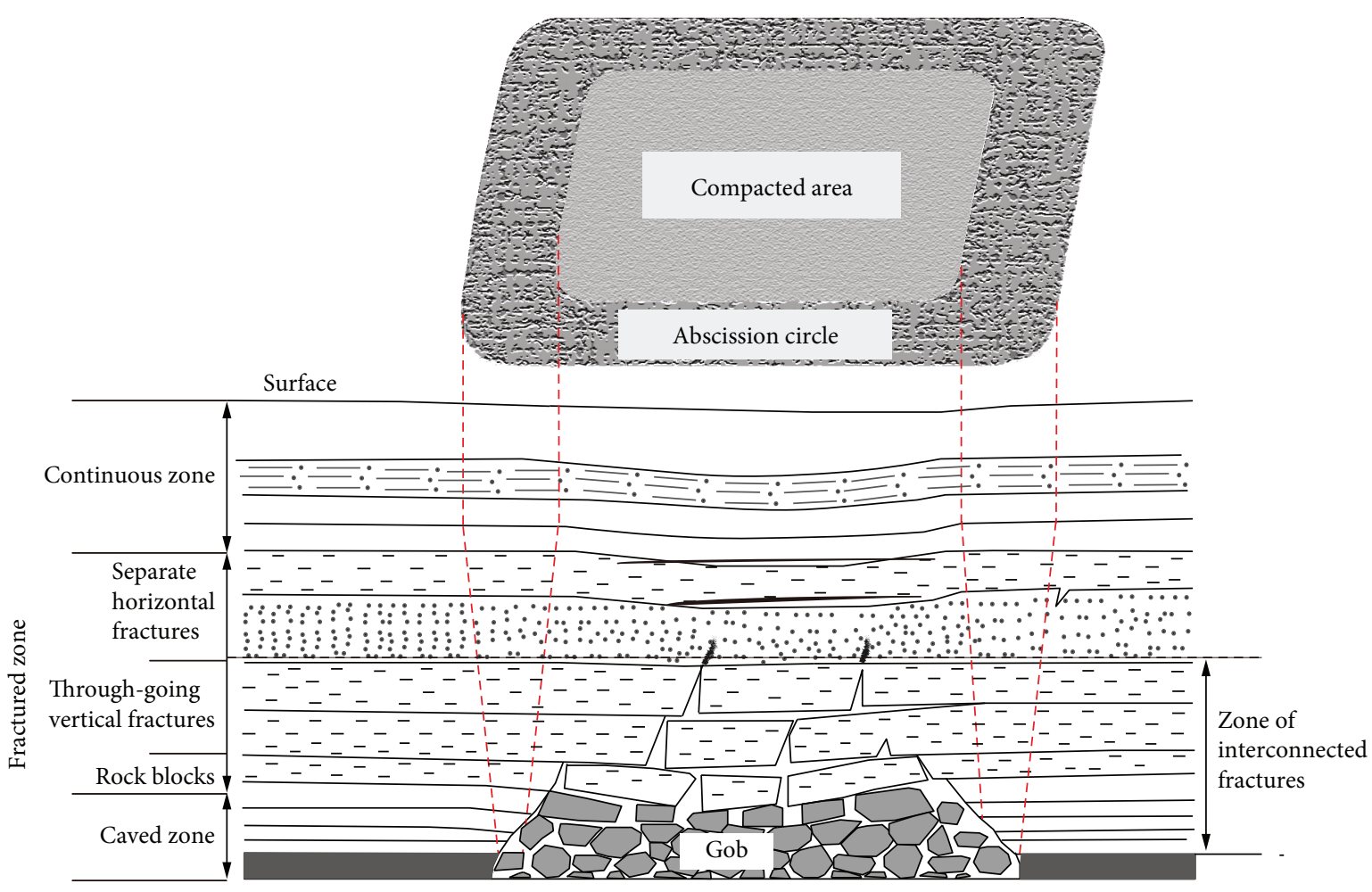

FIGURE 9: Schematic diagram of the "three zones" [19, 41] and "abscission circle" [30, 42].

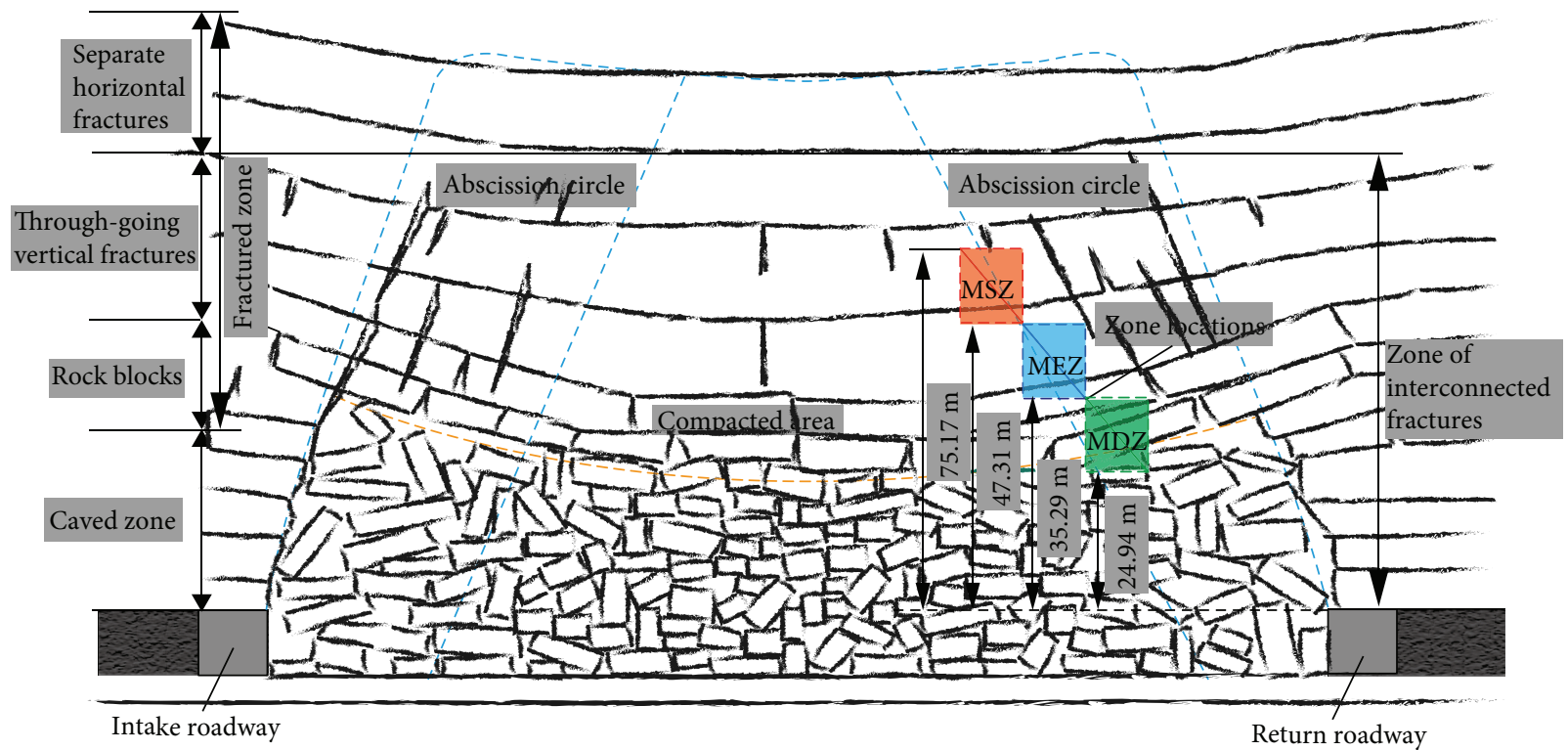

Figure 10: Schematics of the zone divisions in the incline profile of the longwall face.

be lower, where a lower methane flow rate and purity were identified. However, the methane concentration in the upper corner was higher in the two other zones. More effective methane drainage was achieved when the lateral section of the SDB, or a high-level suction tunnel, was arranged in the MEZ.

\section{Data Availability}

Some data used to support the findings of this study are included within the article. Other data used to support the findings of this study are available from the corresponding author upon request. 


\section{Conflicts of Interest}

The authors declare that they have no conflicts of interest.

\section{Acknowledgments}

This research was supported by the National Natural Science Foundation of China $(51504160,51574172)$ and the Joint Funds of the National Natural Science Foundation of China (U1710258, U1710121). This work was also supported by the Program for the Outstanding Innovative Teams of Higher Learning Institutions of Shanxi and the Training Program of First-Class Discipline for Young Academic Backbone of Taiyuan University of Technology.

\section{References}

[1] J. C. Wang, S. L. Yang, Y. Li, L. K. Wei, and H. H. Liu, “Caving mechanisms of loose top-coal in longwall top-coal caving mining method," International Journal of Rock Mechanics and Mining Sciences, vol. 71, pp. 160-170, 2014.

[2] G. R. Feng, S. Y. Hu, Z. Li et al., "Distribution of methane enrichment zone in abandoned coal mine and methane drainage by surface vertical boreholes: a case study from China," Journal of Natural Gas Science and Engineering, vol. 34, pp. 767-778, 2016.

[3] K. Jin, Y. P. Cheng, W. Wang, H. B. Liu, Z. D. Liu, and H. Zhang, "Evaluation of the remote lower protective seam mining for coal mine gas control: a typical case study from the Zhuxianzhuang Coal Mine, Huaibei Coalfield, China," Journal of Natural Gas Science and Engineering, vol. 33, pp. 44-55, 2016.

[4] Z. Aitao and W. Kai, "A new gas extraction technique for high-gas multi-seam mining: a case study in Yangquan Coalfield, China," Environment and Earth Science, vol. 77, no. 4, p. 150, 2018.

[5] C. Zhang, S. H. Tu, Q. S. Bai, G. Y. Yang, and L. Zhang, "Evaluating pressure-relief mining performances based on surface gas venthole extraction data in longwall coal mines," Journal of Natural Gas Science and Engineering, vol. 24, pp. 431-440, 2015.

[6] C. Ö. Karacan, F. A. Ruiz, M. Cotè, and S. Phipps, "Coal mine methane: a review of capture and utilization practices with benefits to mining safety and to greenhouse gas reduction," International Journal of Coal Geology, vol. 86, no. 2-3, pp. 121-156, 2011.

[7] V. Palchik, "Time-dependent methane emission from vertical prospecting boreholes drilled to abandoned mine workings at a shallow depth," International Journal of Rock Mechanics and Mining Sciences, vol. 72, pp. 1-7, 2014.

[8] Y. K. Liu, S. H. Shao, X. X. Wang, L. P. Chang, G. L. Cui, and F. B. Zhou, "Gas flow analysis for the impact of gob gas ventholes on coalbed methane drainage from a longwall gob," Journal of Natural Gas Science and Engineering, vol. 36, pp. 1312-1325, 2016.

[9] F. B. Zhou, T. Q. Xia, X. X. Wang, Y. F. Zhang, Y. N. Sun, and J. S. Liu, "Recent developments in coal mine methane extraction and utilization in China: a review," Journal of Natural Gas Science and Engineering, vol. 31, pp. 437-458, 2016.

[10] N. Szlązak, D. Obracaj, and J. Swolkień, "Methane drainage from roof strata using an overlying drainage gallery,"
International Journal of Coal Geology, vol. 136, pp. 99115, 2014.

[11] N. Guanhua, X. Hongchao, L. Zhao, Z. Lingxun, and N. Yunyun, "Improving the permeability of coal seam with pulsating hydraulic fracturing technique: a case study in Changping coal mine, China," Process Safety and Environmental Protection, vol. 117, pp. 565-572, 2018.

[12] G. H. Ni, Z. Li, and H. C. Xie, "The mechanism and relief method of the coal seam water blocking effect (WBE) based on the surfactants," Powder Technology, vol. 323, pp. 60-68, 2018.

[13] L. Ying-ke, Z. Fu-bao, L. Lang, L. Chun, and H. Shen-yong, "An experimental and numerical investigation on the deformation of overlying coal seams above double-seam extraction for controlling coal mine methane emissions," International Journal of Coal Geology, vol. 87, no. 2, pp. 139-149, 2011.

[14] C. Ö. Karacan, "Analysis of gob gas venthole production performances for strata gas control in longwall mining," International Journal of Rock Mechanics and Mining Sciences, vol. 79, pp. 9-18, 2015.

[15] I. A. Turchaninov, M. A. Iofis, and E. V. Kasparian, Principles of Rock Mechanics, Nedra, Leningrad, Russia, 1977.

[16] H. Kratzsch, Mining Subsidence Engineering, Springer, Berlin, Germany, 1983.

[17] S. Peng, Coal Mine Ground Control, Wiley, New York, NY, USA, 2nd edition, 1986.

[18] B. N. Whittaker and D. J. Reddish, Subsidence: Occurrence, Prediction and Control, Elsevier, Barking, 1989.

[19] V. Palchik, "Formation of fractured zones in overburden due to longwall mining," Environmental Geology, vol. 44, no. 1, pp. 28-38, 2003.

[20] S. F. Wang, X. B. Li, and D. M. Wang, "Void fraction distribution in overburden disturbed by longwall mining of coal," Environment and Earth Science, vol. 75, no. 2, p. 151, 2016.

[21] S. X. Sang, H. J. Xu, L. C. Fang, G. J. Li, and H. Z. Huang, "Stress relief coalbed methane drainage by surface vertical wells in China," International Journal of Coal Geology, vol. 82, no. 3-4, pp. 196-203, 2010.

[22] R. P. Singh and R. N. Yadav, "Prediction of subsidence due to coal mining in Raniganj coalfield, West Bengal, India," Engineering Geology, vol. 39, no. 1-2, pp. 103-111, 1995.

[23] S. K. Das, "Observations and classification of roof strata behaviour over longwall coal mining panels in India," International Journal of Rock Mechanics and Mining Sciences, vol. 37, no. 4, pp. 585-597, 2000.

[24] M. G. Qian and P. W. Shi, Control of Mine Ground Pressure and Strata, China University of Mining and Technology Press, Xuzhou, China, 2003.

[25] M. Christopher, "Multiple-seam mining in the United States: background," in Proceedings of the New Technology for Ground Control in Multiple-Seam Mining, U.S. Department of Health and Human Services, Centers for Disease Control and Prevention, National Institute for Occupational Safety and Health, Pittsburgh Research Laboratory, pp. 3-14, Pittsburgh, PA, USA, 2007.

[26] L. Yuan, H. Guo, B. T. Shen, Q. D. Qu, and J. H. Xue, "Circular overlying zone at longwall panel for efficient methane capture of multiple coal seams with low permeability," Journal of China Coal Society, vol. 36, no. 3, pp. 357-365, 2011.

[27] H. Guo, L. Yuan, B. T. Shen, Q. D. Qu, and J. H. Xue, "Mining-induced strata stress changes, fractures and gas flow 
dynamics in multi-seam longwall mining," International Journal of Rock Mechanics and Mining Sciences, vol. 54, pp. 129139, 2012.

[28] S. G. Li, H. F. Lin, P. X. Zhao, P. Xiao, and H. Y. Pan, "Dynamic evolution of mining fissure elliptic paraboloid zone and extraction coal and gas," Journal of China Coal Society, vol. 39, no. 8, pp. 1455-1462, 2014.

[29] F. Q. Gao, D. Stead, and J. Coggan, "Evaluation of coal longwall caving characteristics using an innovative UDEC Trigon approach," Computers and Geotechnics, vol. 55, pp. 448-460, 2014.

[30] Z. Y. Qin, L. Yuan, H. Guo, and Q. D. Qu, "Investigation of longwall goaf gas flows and borehole drainage performance by CFD simulation," International Journal of Coal Geology, vol. 150-151, pp. 51-63, 2015.

[31] Q. D. Qu, J. L. Xu, R. L. Wu, W. Qin, and G. Z. Hu, “Threezone characterisation of coupled strata and gas behaviour in multi-seam mining," International Journal of Rock Mechanics and Mining Sciences, vol. 78, pp. 91-98, 2015.

[32] Z. W. Wang, T. Ren, and Y. P. Cheng, "Numerical investigations of methane flow characteristics on a longwall face part I: methane emission and base model results," Journal of Natural Gas Science and Engineering, vol. 43, pp. 242-253, 2017.

[33] Z. W. Wang, T. Ren, and Y. P. Cheng, "Numerical investigations of methane flow characteristics on a longwall face part II: parametric studies," Journal of Natural Gas Science and Engineering, vol. 43, pp. 254-267, 2017.

[34] G. R. Feng, A. Zhang, S. Y. Hu et al., "A methodology for determining the methane flow space in abandoned mine gobs and its application in methane drainage," Fuel, vol. 227, pp. 208217, 2018.

[35] F. G. Bell, Engineering in Rock Masses, Elsevier, Amsterdam, Netherlands, 2013.

[36] V. Palchik, "Bulking factors and extents of caved zones in weathered overburden of shallow abandoned underground workings," International Journal of Rock Mechanics and Mining Sciences, vol. 79, pp. 227-240, 2015.

[37] J. P. Du and L. Q. Wang, Special Coal Mining Method, China University of Mining and Technology Press, Xuzhou, China, 2003.

[38] Y. C. Xu, J. C. Li, and S. Q. Liu, "Calculation formula of "two-zone" height of overlying strata and its adaptability analysis," Coal Mining Technology, vol. 16, no. 2, pp. 4-8, 2011.

[39] S. Y. Hu, Z. Li, G. R. Feng et al., "Changes on methane concentration after $\mathrm{CO}_{2}$ injection in a longwall gob: a case study," Journal of Natural Gas Science and Engineering, vol. 29, pp. 550-558, 2016.

[40] H. T. Liu, N. J. Ma, J. Li, W. W. Zhang, and S. P. Zhang, "Evolution and distribution characteristics of roof shallow fissure channel," Journal of China Coal Society, vol. 37, no. 9, pp. 1451-1455, 2012.

[41] V. Palchik, "Localization of mining-induced horizontal fractures along rock layer interfaces in overburden: field measurements and prediction," Environmental Geology, vol. 48, no. 1, pp. 68-80, 2005.

[42] M. G. Qian and J. L. Xu, "Study on ozone characteristics of mining-induced fracture distribution in overlying strata," Journal of China Coal Society, vol. 5, pp. 466-469, 1998. 

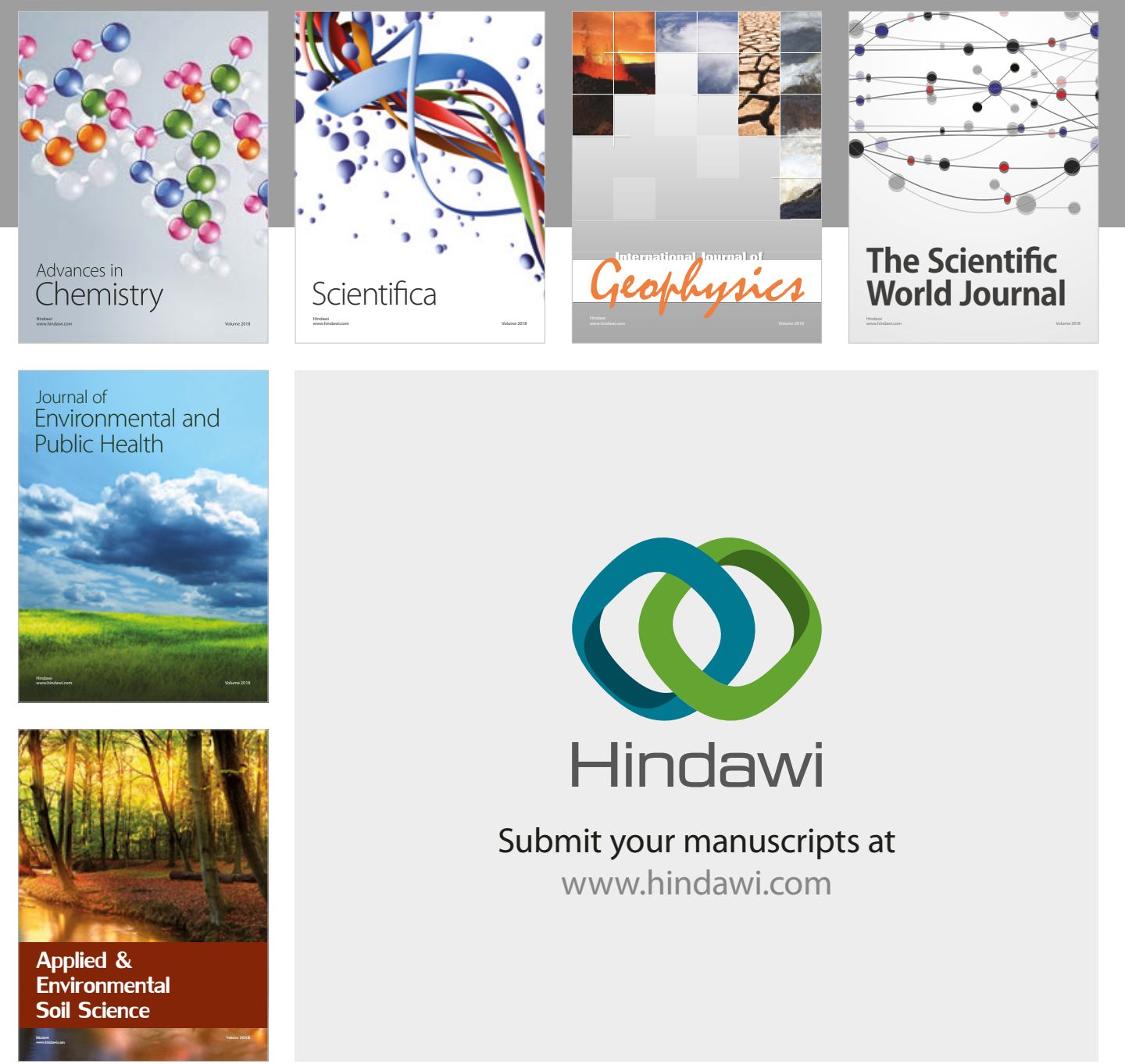

The Scientific

\section{World Journal}
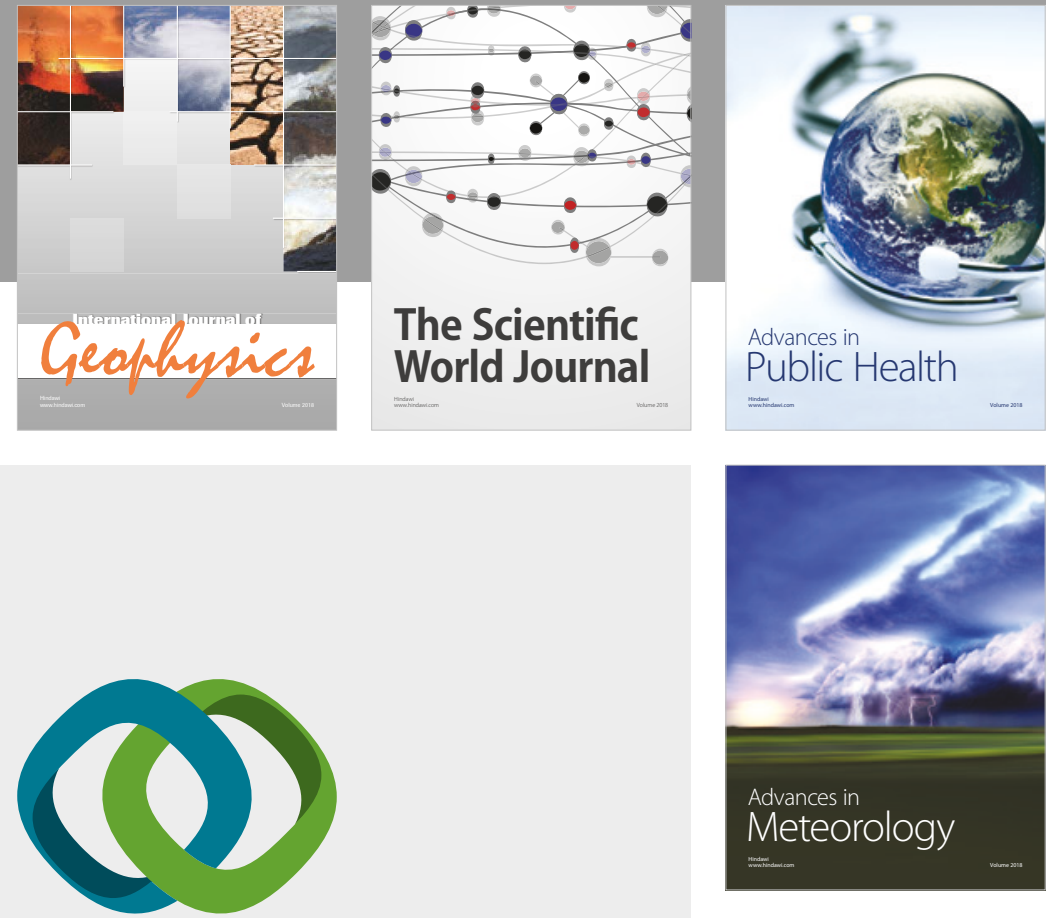

Advan

Public Health

\section{Hindawi}

Submit your manuscripts at

www.hindawi.com
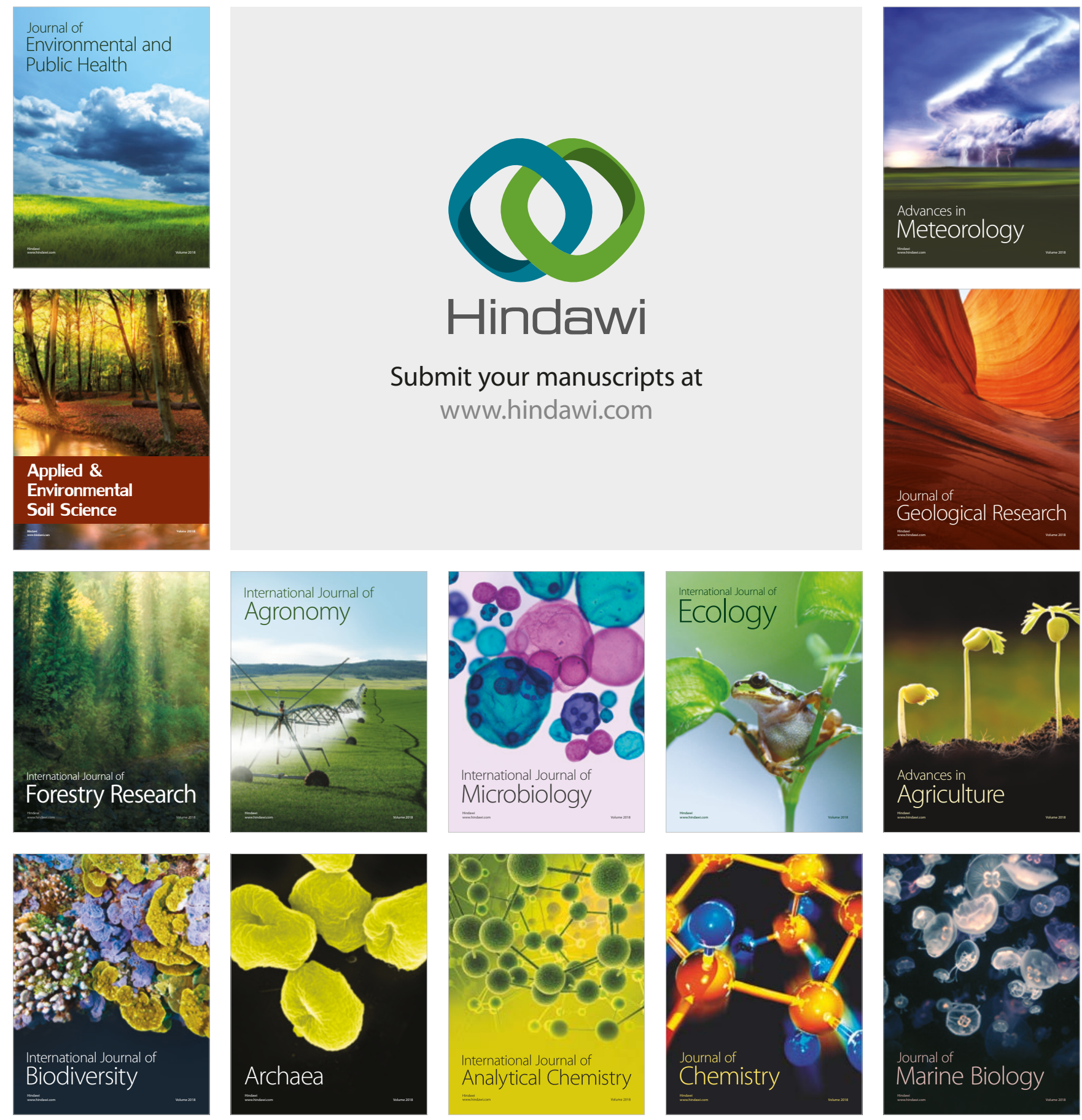